\title{
Different Characteristics of Ex-Smokers and Current Smokers with COPD: A Cross-Sectional Study in China
}

This article was published in the following Dove Press journal: International Journal of Chronic Obstructive Pulmonary Disease

\author{
Cong Liu' \\ Wei Cheng (D) \\ Yuqin Zeng' \\ Zijing Zhou' \\ Yiyang Zhao (D) \\ Jiaxi Duan' \\ Ran Wang (D' \\ Tian Sun' \\ Xin Li (iD $)^{2}$ \\ Zhi Xiang ${ }^{3}$ \\ Ping Chen' \\ Si Lei ${ }^{\prime}$
}

'Department of Pulmonary and Critical Care Medicine, The Second Xiangya Hospital, Central South University; Research Unit of Respiratory Disease, Central South University; Diagnosis and Treatment Center of Respiratory Disease, Central South University, Changsha 4I00II, Hunan, People's Republic of China; ${ }^{2}$ Department of Respiratory Diseases, Hunan Prevention and Treatment Institute for Occupational Diseases, Changsha 410007, Hunan, People's Republic of China; ${ }^{3}$ Department of Respiratory Diseases, The First People's Hospital of Huaihua, Affiliated to University of South China, Huaihua 4I8000, Hunan, People's Republic of China
Correspondence: Ping Chen; Si Lei Email pingchen073।@csu.edu.cn; leisi083I@csu.edu.cn
Purpose: Chronic obstructive pulmonary disease (COPD), usually caused by tobacco smoking, is increased in China. Smoking cessation is the first step in COPD management. Data on predictors of smoking cessation are sparse in COPD patients in China. We aim to find the differences in the clinical characteristics between ex-smokers and current smokers with COPD to determine the factors related to smoking cessation.

Patients and Methods: From outpatient departments of 12 hospitals in Hunan and Guangxi provinces, a total of 4331 patients were included. Information on demographic and sociological data, lung function, and modified Medical Research Council (mMRC) dyspnea scale scores were recorded. Patients were divided into an ex-smokers group and a current smokers group based on whether they gave up smoking. A logistic regression analysis was performed to analyze the factors associated with smoking cessation.

Results: Of the total, the mean age was $62.9 \pm 8.5$ years, and $47.3 \%$ were ex-smokers. Compared with the current smokers, the ex-smokers were older, and had heavier dyspnea, more severe airflow limitation, fewer pack-years, shorter smoking duration, and a higher proportion of Global Initiative for Chronic Obstructive Lung Disease (GOLD) groups C and D. The logistic regression model showed that smoking cessation was negatively correlated with widowhood, years of smoking, and forced expiratory volume in 1 second (FEV1), but was positively correlated with age, education level, amount smoked, mMRC score, GOLD grades, and GOLD groups.

Conclusion: Among patients with COPD, more than half still smoked. In the group of patients who quit smoking, many of them quit rather late in age after they had significant symptoms. Several predictors of smoking cessation were identified, indicating that exsmokers differ substantially from continuing smokers. This should be taken into account in smoking-cessation interventions.

Keywords: COPD, cross-sectional study, ex-smokers and current smokers, smoking cessation

\section{Introduction}

Chronic obstructive pulmonary disease (COPD) is characterized by persistent respiratory symptoms and airflow limitation that are usually caused by significant exposure to noxious particles or gases. ${ }^{1}$ The latest prevalence of COPD among Chinese people over the age of 40 is $13.7 \%,^{2}$ a higher rate than before, ${ }^{3}$ and approximately half of the men with COPD still smoke. Smoking is the leading cause of COPD, and quitting smoking is the first step in managing the disease. ${ }^{1}$ Smoking cessation improves symptoms, ${ }^{4}$ slows down the decline in forced expiratory volume in 1 second (FEV1), ${ }^{5}$ and reduces hospital admissions and the risk of 
death. ${ }^{6-8}$ In western countries, there are data on predictors of successful cessation among patients with COPD. In the US, a cross-sectional study found that ex-smokers were older than current smokers. ${ }^{9}$ Patients with COPD who were younger, lived alone, had heavier dyspnea, were in a milder COPD group, and had less airway obstruction were less likely to quit. ${ }^{10,11}$ A Turkish cross-sectional study showed that, among COPD patients, current smokers were younger, had a lower Global Initiative for Chronic Obstructive Lung Disease (GOLD) stage, and had a better 6-minute walking distance than former smokers. ${ }^{12}$ In China, an ingrained ritual of gifting and sharing cigarettes strongly contributes to smoking initiation as well as failure to quit smoking among Chinese males. ${ }^{13}$ A small portion of smokers stopped smoking with the diagnosis of a tobacco-related chronic disease. ${ }^{14,15}$ Chen found that airway obstruction was a predictor associated with smoking cessation in the general population. ${ }^{16}$ However, data associated with smoking cessation are sparse in COPD patients in China. We aim to understand the characteristics of ex-smokers and current smokers with COPD to identify important factors of smoking cessation.

\section{Patients and Methods Study Participant}

This was a sub-analysis of a multicenter, prospective cohort study, which aimed to understand the characteristics associated with ex-smokers and current smokers with COPD to identify factors of smoking cessation (Registration number: ChiCTR-POC-17,010,431). The study was approved by the institutional review board of the Second Xiangya Hospital of Central South University (Hunan, China) and conducted in accordance with the Declaration of Helsinki. Initially, we included 7310 patients who had been diagnosed with COPD and registered from the outpatient department of 12 hospitals in Hunan and Guangxi provinces in China from December 2016 to October 2019. COPD was defined by spirometry [after post-bronchodilator FEV1/forced vital capacity (FVC) <0.7] based on GOLD 2016. Patients for whom smoking history was not registered, those with fewer than 10 pack-years, and those who never smoked were excluded.

\section{Data Collection and Definitions}

All participants in this study provided written informed consent. Information on age, sex, marital status, education level, body mass index (BMI), smoking status, lung function, and modified Medical Research Council (mMRC) dyspnea scale scores were recorded. Smoking information was selfreported by patients. A smoker was defined as continuous smoking exposure of more than 10 pack-years. Patients who had sustained abstinence for more than 6 months were former smokers. Never-smokers who had smoked no more than 100 cigarettes in their lifetime. The mMRC was used to assess the degree of dyspnea. For disease severity, participants were classified into GOLD grades $1-4$ and ABCD groups according to GOLD (2016).

\section{Patient Selection}

A total of 4331 patients were included in the study (including 2047 ex-smokers and 2284 current smokers), excluding 2979 patients (including 1450 patients without smoking history, 191 patients smoking less than 10 packyears, 1338 never-smokers).

\section{Statistical Analysis}

SPSS 26. 0 (IBM, Armonk, NY, USA) was used for statistical analyses. Data were provided as mean and standard deviation for quantitative variables and as absolute numbers and percentages for qualitative variables. The Kolmogorov-Smirnov test was used to analyze the distribution of variables. In the bivariate analysis, the Student $t$-test for independent variables was used to analyze normally distributed variables, and the Mann-Whitney $U$-test was used to analyze variables with non-normal distributions. Qualitative variables were compared using the chisquare test. The associations were considered significant at $\mathrm{p}<0.05$. The variously adjusted odds ratios (ORs) were calculated using multivariate logistic regression.

\section{Results}

Of the 4331 patients with COPD included (Figure 1), the mean age was $62.9 \pm 8.5$ years, and $98.9 \%$ were male. Most of the patients had a high school education or below (95\%), had an mMRC score of 2 or higher $(68.6 \%)$, and were in GOLD groups B to D (79.7\%). Of the participants, $47.3 \%$ were ex-smokers.

The different characteristics of the former smokers group and the current smokers group were shown in Table 1. Compared with the current smokers, the exsmokers were older $(64.1 \pm 8.5$ vs. $61.9 \pm 8.4, p<0.01)$, had higher mMRC scores $(2.15 \pm 0.9$ vs. $1.85 \pm 1.0, p<0.01)$, had more severe airflow limitation (mean FEV1\% predicted of $47.5 \%$ vs. $52.3 \%, p<0.01)$, had fewer pack-years $(42.3$ \pm 26.9 vs. $46.7 \pm 25.1, p<0.01$ ), had less smoking duration 


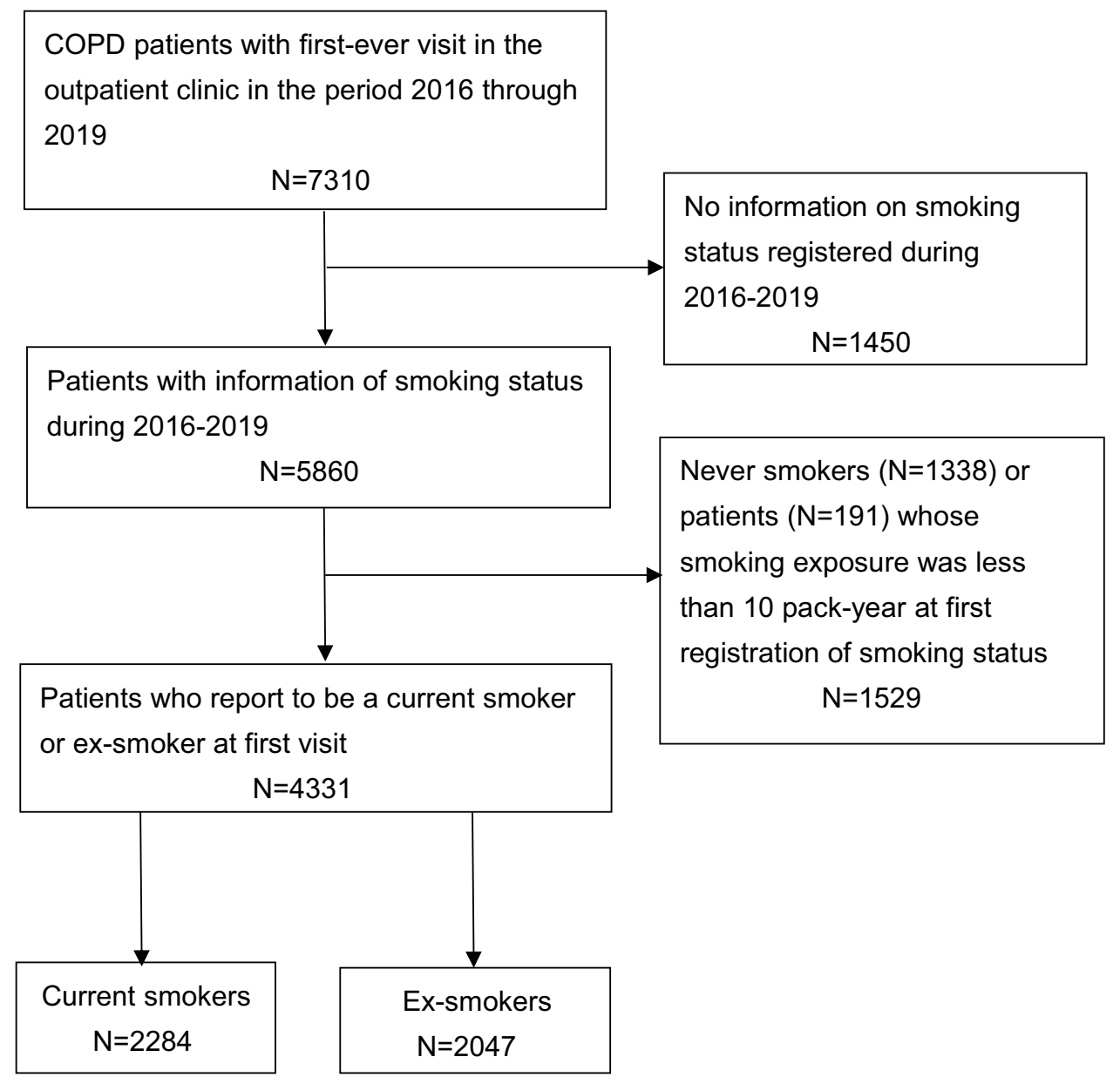

Figure I Flow chart for patient selection.

Abbreviation: COPD, chronic obstructive pulmonary disease.

$(30.5 \pm 11.3$ vs. $36.6 \pm 10.5, p<0.01)$, and had a greater proportion of GOLD groups C and D (59.6\% vs. $48.1 \%$, $p<0.01)$.

A logistic regression analysis was used to find the significant factors associated with smoking cessation. According to COPD severity, FEV1 was negative with smoking cessation, with an OR of $0.699 \quad(95 \%$ $\mathrm{CI}=0.595-0.822)$. Patients were more likely to quit if they had worse GOLD groups, with the OR of 1.741 (95\% CI=1.353-2.172) for GOLD B, $1.371 \quad(95 \%$ $\mathrm{CI}=1.015-1.852)$ for GOLD $\mathrm{C}$, and $2.516 \quad(95 \%$ $\mathrm{CI}=2.026-3.124)$ for GOLD D compared with GOLD A. The likelihood of smoking cessation was higher among patients with severe and very severe COPD (OR $1.235,95 \% \mathrm{CI}=1.050-1.452$ ) compared mild and moderate COPD, and among patients with mMRC of 2 or greater (OR 3.616, 95\% CI=2.892-4.523) compared with an mMRC of less than 2 (Table 2). According to sociodemographic characteristics, patients were less likely to quit who were younger with an OR of $0.348 \quad(95 \%$ $\mathrm{CI}=0.167-0.727$ ) for patients less than 45 years of age and $0.409(95 \% \mathrm{CI}=0.343-0.489)$ for patients aged 45 to 64 compared with those aged 65 or above, who had graduated from high school with an OR of $0.695(95 \%$ $\mathrm{CI}=0.438-0.897)$ compared with those receiving a college education, or who were widowed (OR 0.484, 95\% $\mathrm{CI}=0.288-0.814)$. The number of years of smoking (OR $0.930,95 \% \mathrm{CI}=0.922-0.937$ ) was negatively associated with smoking cessation, but patients who consumed two or more packs per day were more likely to quit (OR 1.488, 95\% CI=1.243-1.781) compared with those who consumed less than two packs per day (Table 3).

\section{Discussion}

The cross-sectional study including outpatients with COPD compares the characteristics between current smokers and ex-smokers and analyzes the factors associated with smoking cessation. More than half of the participants 
Table I Differences in Clinical Characteristics Between Patients with COPD: of Former Smokers Group and versus Current Smokers

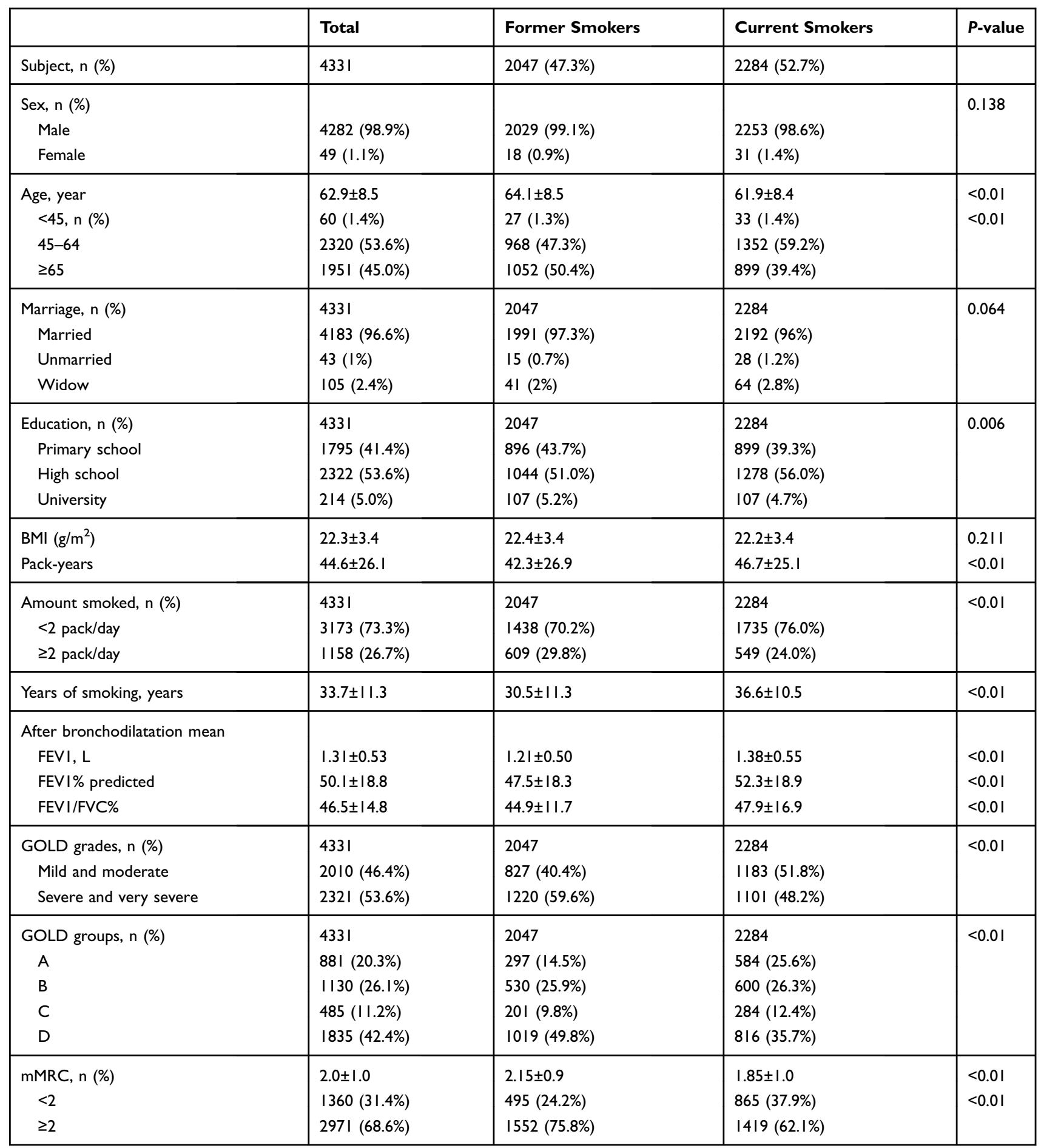

Notes: Data are shown as No. (\%) or mean \pm standard deviation. The associations were considered significant at $p<0.05$.

Abbreviations: BMI, body mass index (assessed as kg/m2); COPD, chronic obstructive pulmonary disease; FEVI, forced expiratory volume in one second; FVC, forced vital capacity; GOLD, Global Initiative for Chronic Obstructive Lung Disease; mMRC, modified Medical Research Council.

are still smoking. Compared with the current smoking patients with COPD, ex-smokers with COPD were older, were more dyspneic, and had greater airflow limitation. These findings suggest that many patients continue smoking until they have obvious symptoms. In China, patients with COPD typically do not come to the hospital until they have significant symptoms, resulting in a failure to receive timely diagnosis and treatment. ${ }^{17}$ In fact, even in patients with severe COPD, smoking cessation slows the acceleration of lung function, ${ }^{18}$ increases survival, ${ }^{7}$ and reduces 
Table 2 Factors Associated with Smoking Cessation According to COPD Severity in Multivariate Analysis

\begin{tabular}{|c|c|c|c|}
\hline Variable & OR & $95 \% \mathrm{Cl}$ & $P$-value \\
\hline FEVI* & 0.699 & $0.595-0.822$ & $<0.001$ \\
\hline $\begin{array}{l}\text { GOLD grades** } \\
\text { Mild and moderate } \\
\text { Severe and very severe }\end{array}$ & $\begin{array}{l}\text { Reference } \\
\text { I. } 235\end{array}$ & $1.050-1.452$ & 0.011 \\
\hline $\begin{array}{l}\text { GOLD groups**** } \\
\text { A } \\
\text { B } \\
\text { C } \\
\text { D }\end{array}$ & $\begin{array}{l}\text { Reference } \\
1.714 \\
1.371 \\
2.516\end{array}$ & $\begin{array}{l}1.353-2.172 \\
1.015-1.852 \\
2.026-3.124\end{array}$ & $\begin{array}{l}<0.001 \\
0.04 \\
<0.001\end{array}$ \\
\hline $\begin{array}{c}\mathrm{mMRC}^{*} \\
\quad<2 \\
\geq 2\end{array}$ & $\begin{array}{l}\text { Reference } \\
3.616\end{array}$ & $2.892-4.523$ & $<0.001$ \\
\hline
\end{tabular}

Notes: Values are expressed as odds ratio (OR) and $95 \%$ confidence interval $(\mathrm{Cl})$. The associations were considered significant at $p<0.05$. *Multivariate analysis was adjusted for age, sex, marriage, education, years of smoking, amount smoked, FEVI, and $\mathrm{mMRC}$ score. **Multivariate analysis was adjusted for age, sex, marriage, education, years of smoking, amount smoked, GOLD grades, and mMRC score. ***Multivariate analysis was adjusted for age, sex, marriage, education, years of smoking, amount smoked, GOLD groups, and mMRC score.

Abbreviations: COPD, chronic obstructive pulmonary disease; FEVI, forced expiratory volume in one second; GOLD, Global Initiative for Chronic Obstructive Lung Disease; mMRC, modified Medical Research Council; OR, odds ratio; $95 \% \mathrm{Cl}, 95 \%$ confidence interval.

smoking-related complications. ${ }^{19}$ Therefore, in the management of COPD, we should find smokers with early airway obstruction and provide smoking cessation to slow the natural progression of COPD. ${ }^{20,21}$

More importantly, the present study found some factors related to smoking cessation. We observed a relationship between the milder COPD group defined by the GOLD A-D groups and the lower likelihood of smoking cessation. A previous study also found the relation between GOLD A-D groups and smoking cessation. ${ }^{10}$ The present study found a significant negative correlation between FEV1 and smoking cessation. A study of the general population (not COPD patients) found a link between a reduced FEV1 and quitting smoking. ${ }^{22}$ We observed that patients with a lower degree of dyspnea are less likely to quit, consistent with two previous studies. ${ }^{10,23}$ One study showed that making smokers aware of the risks of smoking affected decisions about continued smoking and intentions to quit. $^{24}$ In China, being diagnosed with a disease caused by smoking was the important reason for smokers to quit. ${ }^{14,25}$ After severe symptoms due to smoking occurred, patients with COPD were more likely to quit. We observed that younger age was associated with
Table 3 Factors Associated with Smoking Cessation According to Sociodemographic Characteristics in Multivariate Analysis

\begin{tabular}{|c|c|c|c|}
\hline Variable* & OR & $95 \% \mathrm{Cl}$ & $P$-value \\
\hline \multicolumn{4}{|l|}{ Age } \\
\hline$\geq 65$ & Reference & & \\
\hline $45-64$ & 0.409 & $0.343-0.489$ & $<0.001$ \\
\hline$<45$ & 0.348 & $0.167-0.727$ & 0.005 \\
\hline \multicolumn{4}{|l|}{ Sex } \\
\hline Male & Reference & & \\
\hline Female & 0.574 & $0.25 \mathrm{I}-1.135$ & 0.105 \\
\hline \multicolumn{4}{|l|}{ Marriage } \\
\hline Married & Reference & & \\
\hline Unmarried & 0.522 & $0.238-1.146$ & 0.105 \\
\hline Widowed & 0.484 & $0.288-0.814$ & 0.006 \\
\hline \multicolumn{4}{|l|}{ Education } \\
\hline University & Reference & & \\
\hline High school & 0.627 & $0.438-0.897$ & 0.011 \\
\hline Primary school & 0.695 & $0.483-1.000$ & 0.05 \\
\hline Years of smoking & 0.930 & $0.922-0.937$ & $<0.001$ \\
\hline \multicolumn{4}{|l|}{ Amount smoked } \\
\hline$<2$ pack/day & Reference & & \\
\hline$\geq 2 \mathrm{pack} /$ day & 1.488 & $|.243-1.78|$ & $<0.001$ \\
\hline
\end{tabular}

Notes: Values are expressed as odds ratio (OR) and $95 \%$ confidence interval $(\mathrm{Cl})$. $\mathrm{P}<0.05$ has statistically significant values. *Multivariate analysis was adjusted for age, sex, marriage, education, years of smoking, amount smoked, FEVI, and mMRC score.

Abbreviations: FEVI, forced expiratory volume in one second; mMRC, modified Medical Research Council; OR, odds ratio; $95 \% \mathrm{Cl}$, $95 \%$ confidence interval.

lower likelihood of quitting, consistent with previous studies of the general population and patient cohorts. ${ }^{26-28} \mathrm{We}$ found that widowed patients were less likely to quit smoking than married patients. Maybe most of the widowed patients lived alone. Tøttenborg SS found that patients with COPD living alone had more difficulty quitting than those living with someone. ${ }^{10}$ In the general population, smokers who were married or living with partners were more likely to quit smoking. ${ }^{26}$ However, living with smokers was associated with failure to quit, especially if family members were doctors or nurses who smoke. ${ }^{23}$ We discovered that lower education level was associated with lower probability of smoking cessation, similar with the study of the general population. ${ }^{26}$ We discovered that patients consuming more than two packs per day were more likely to quit. Wang found that health shocks decreased the likelihood of heavy smoking ( $>20$ cigarettes per day) by $41.6 \%$ versus the combined moderate and light categories, and increased the likelihood of quitting by $85.3 \%$ for ever-smokers. ${ }^{29}$ After serious symptoms occurred, heavy smokers were more likely to quit. We 
found that there was a negative correlation between smoking cessation and smoking duration. One study of the general population also observed that compared with smoking for more than 10 years, people smoking for less were more likely to quit. ${ }^{30}$

Our study has limitations. This is a cross-sectional study; therefore, we cannot make conclusions about direction of causality. We also cannot explain the mechanisms of factors associated with smoking cessation, and they need to be further explored. Patients were recruited from the outpatient clinic and, therefore, possibly had more severe clinical symptoms than a patient with COPD in the community. The history of smoking was self-reported by the patients and was not verified by an exhaled carbon monoxide level.

In summary, among smokers with COPD, more than half were still smoking. Even among the small portion of patients who had given up smoking, many of them quit smoking rather late and due to having a significant symptom. Several factors about smoking cessation were identified, indicating that ex-smokers differ substantially from continuing smokers. This should be taken into account in smoking-cessation interventions.

\section{Abbreviations}

BMI, body mass index; CI, confidence interval; COPD, chronic obstructive pulmonary disease; FEV1, forced expiratory volume in 1 second; FVC, forced vital capacity; GOLD, Global Initiative for Chronic Obstructive Lung Disease; mMRC scale, modified Medical Research Council scale; PFT, pulmonary function test.

\section{Data Sharing Statement}

All data generated or analysed during this study were included in this published article and no further data will be shared.

\section{Statement of Ethics}

The study was approved by the institutional review board of the Second Xiangya Hospital of Central South University (Hunan, China) and conducted in accordance with the Declaration of Helsinki. All participants in the cohorts provided written informed consent.

\section{Acknowledgments}

We thank the participants who contributed to this study. For continuous support, assistance, and cooperation, we thank Zhi-wen Wang, Guo-guo Zhong, Min Qian, Tian
Sun, Chu-Juan Tang, Qing Song, Ran Wang, Zi-hang Zeng, Qian Li (The Second Xiangya Hospital of Central South University), Ying-qun Zhu, Mi Yang (The Third Hospital of Changsha), Ming Chen (The No.1 Traditional Chinese Medicine Hospital in Changde), Ling-mei Huang (The First People's Hospital of Yueyang), Yi liu, Rong Yi (The Affiliated Zhuzhou Hospital of Xiangya School of Medicine CSU), Yongliang Jiang, Mei-ling Zhou (The First People's Hospital of Huaihua), Ming-yan Jiang, Cheng-feng Song (Central Hospital of Xiangtan), Wei-ming Feng (Central Hospital of Hengyang), Qi-yang Liu, Kai Ye (The Second People's Hospital of Guilin), Li-bin Ma, Li-li Zhao, Shuyuan Zhu (Affiliated Hospital of Guilin Medical University), Feng Gao, Ying Xiao (Guilin People's Hospital).

\section{Author Contributions}

All authors made substantial contributions to conception and design, acquisition of data, or analysis and interpretation of data; took part in drafting the article or revising it critically for important intellectual content; gave final approval of the version to be published; and agree to be accountable for all aspects of the work.

\section{Funding}

This work was supported by grants from the National Natural Science Foundation of China (NSFC, Grants 81770046 to Chen Ping) and Xiangya Mingyi grant (2013).

\section{Disclosure}

None of the authors have a conflict of interest.

\section{References}

1. Global Initiative for Chronic Obstructive Lung Disease (GOLD). Global strategy for the diagnosis, management, and prevention of chronic obstructive pulmonary disease. 2016. Available from: http:// goldcopd.org/. Accessed January 5, 2016.

2. Wang C, Xu J, Yang L, et al. Prevalence and risk factors of chronic obstructive pulmonary disease in China (the China Pulmonary Health [CPH] study): a national cross-sectional study. Lancet. 2018;391 (10131):1706-1717. doi:10.1016/S0140-6736(18)30841-9

3. Zhong N, Wang C, Yao W, et al. Prevalence of chronic obstructive pulmonary disease in China: a large, population-based survey. Am J Respir Crit Care Med. 2007;176(8):753-760. doi:10.1164/rccm.20 0612-1749OC

4. Willemse BW, Postma DS, Timens W, et al. The impact of smoking cessation on respiratory symptoms, lung function, airway hyperresponsiveness and inflammation. Eur Respir J. 2004;23(3):464-476. doi:10.1183/09031936.04.00012704 
5. Lee PN, Fry JS. Systematic review of the evidence relating FEV1 decline to giving up smoking. BMC Med. 2010;8:84. doi:10.1186/ 1741-7015-8-84

6. Josephs L, Culliford D, Johnson M, et al. Improved outcomes in ex-smokers with COPD: a UK primary care observational cohort study. Eur Respir J. 2017;49:1602114. doi:10.1183/13993003.021 14-2016

7. Godtfredsen NS, Lam TH, Hansel TT, et al. COPD-related morbidity and mortality after smoking cessation: status of the evidence. Eur Respir J. 2008;32:844-853. doi:10.1183/09031936.00160007

8. He Y, Jiang B, Li LS, et al. Changes in smoking behavior and subsequent mortality risk during a 35-year follow-up of a cohort in Xi'an, China. Am J Epidemiol. 2014;179:1060-1070. doi:10.1093/ aje/kwu011

9. Adams SG, Pugh JA, Kazis LE, et al. Characteristics associated with sustained abstinence from smoking among patients with COPD. Am $J$ Med. 2006;119(5):441-447. doi:10.1016/j.amjmed.2005.09.055

10. Tottenborg SS, Thomsen RW, Johnsen SP, et al. Determinants of smoking cessation in patients with COPD treated in the outpatient setting. Chest. 2016;150(3):554-562. doi:10.1016/j.chest.2016.05. 020

11. Bednarek M, Gorecka D, Wielgomas J, et al. Smokers with airway obstruction are more likely to quit smoking. Thorax. 2006; 61:869-873. doi:10.1136/thx.2006.059071

12. Karadogan D, Onal O, Sahin DS, et al. Factors associated with current smoking in COPD patients: across-sectional study from the Eastern Black Sea region of Turkey. Tob Induc Dis. 2018;16:22. doi: $10.18332 / \mathrm{tid} / 90665$

13. Rich ZC, Xiao S. Tobacco as a social currency: cigarette gifting and sharing in China. Nicotine Tob Res. 2012;14(3):258-263. doi:10.10 93/ntr/ntr156

14. Wang R, Jiang Y, Yao C, et al. Prevalence of tobacco related chronic diseases and its role in smoking cessation among smokers in a rural area of Shanghai, China: a cross sectional study. BMC Public Health. 2019;19(1):753. doi:10.1186/s12889-019-7110-9

15. Kurmi OP, Li L, Wang J, et al. COPD and its association with smoking in the Mainland China: a cross-sectional analysis of 0.5 million men and women from ten diverse areas. Int J Chron Obstruct Pulmon Dis. 2015;10:655-665. doi:10.2147/COPD.S75454

16. Chen J, Chen Y, Chen P, et al. Effectiveness of individual counseling for smoking cessation in smokers with chronic obstructive pulmonary disease and asymptomatic smokers. Exp Ther Med. 2014;7(3):71 6-720. doi:10.3892/etm.2013.1463
17. Fang X, Wang X, Bai C. COPD in China: the burden and importance of proper management. Chest. 2011;139(4):920-929. doi:10.1378/ chest.10-1393

18. Pride NB. Smoking cessation: effects on symptoms, spirometry and future trends in COPD. Thorax. 2001;56(Suppl 2):ii7-ii10.

19. Thomsen M, Nordestgaard BG, Vestbo J, et al. Characteristics and outcomes of chronic obstructive pulmonary disease in never smokers in Denmark: a prospective population study. Lancet Respir Med. 2013;1(7):543-550. doi:10.1016/S2213-2600(13)70137-1

20. Tashkin DP, Murray RP. Smoking cessation in chronic obstructive pulmonary disease. Respir Med. 2009;103(7):963-974. doi:10.1016/j. rmed.2009.02.013

21. Bai JW, Chen XX, Liu S, et al. Smoking cessation affects the natural history of COPD. Int J Chron Obstruct Pulmon Dis. 2017;12: 3323-3328. doi:10.2147/COPD.S150243

22. Godtfredsen NS, Prescott E, Osler M, et al. Predictors of smoking reduction and cessation in a cohort of Danish moderate and heavy smokers. Prev Med. 2001;33(1):46-52. doi:10.1006/pmed.2001.0852

23. Lou $\mathrm{P}, \mathrm{Zhu} \mathrm{Y}$, Chen $\mathrm{P}$, et al. Supporting smoking cessation in chronic obstructive pulmonary disease with behavioral intervention: a randomized controlled trial. BMC Fam Pract. 2013;14(1):91. doi:10.1186/1471-2296-14-91

24. Lin W, Sloan F. Risk perceptions and smoking decisions of adult Chinese men. $J$ Health Econ. 2015;39:60-73. doi:10.1016/j. jhealeco.2014.11.006

25. Wang J, Li C, Jia C, et al. Smoking, smoking cessation and tobacco control in rural China: a qualitative study in Shandong Province. BMC Public Health. 2014;14(1):916. doi:10.1186/1471-2458-14-916

26. Lee CW, Kahende J. Factors associated with successful smoking cessation in the United States, 2000. Am J Public Health. 2007;97:1503-1509. doi:10.2105/AJPH.2005.083527

27. Toljamo T, Kaukonen M, Nieminen P, et al. Early detection of COPD combined with individualized counselling for smoking cessation: a two-year prospective study. Scand J Prim Health Care. 2010;28 (1):41-46. doi:10.3109/02813431003630105

28. Kupiainen H, Kinnula VL, Lindqvist A, et al. Successful smoking cessation in COPD: association with comorbidities and mortality. Pulm Med. 2012;2012:725024. doi:10.1155/2012/725024

29. Wang Q, Rizzo JA, Fang H. Changes in smoking behaviors following exposure to health shocks in China. Int J Environ Res Public Health. 2018;15(12):2905. doi:10.3390/ijerph15122905

30. Yang TZ, Abdullah AS, Mustafa J, et al. Factors associated with smoking cessation among Chinese adults in rural China. Am J Health Behav. 2009;33(2):125-134. doi:10.5993/AJHB.33.2.2

International Journal of Chronic Obstructive Pulmonary Disease

Dovepress

\section{Publish your work in this journal}

The International Journal of COPD is an international, peer-reviewed journal of therapeutics and pharmacology focusing on concise rapid reporting of clinical studies and reviews in COPD. Special focus is given to the pathophysiological processes underlying the disease, intervention programs, patient focused education, and self management protocols. This journal is indexed on PubMed Central, MedLine and CAS. The manuscript management system is completely online and includes a very quick and fair peer-review system, which is all easy to use. Visit http://www.dovepress.com/testimonials.php to read real quotes from published authors. 